\title{
Tribological advancement - strategies and effects towards emissions and global energy consumption
}

\author{
Masjuki Hassan ${ }^{1, *}$, Syahir Amzar Zulkifli ${ }^{1}$, Harith Hasnul $^{1}$, and Ashraf Yusoff $^{1}$ \\ ${ }^{1}$ Centre for Energy Sciences, Department of Mechanical Engineering, Faculty of Engineering, \\ University of Malaya, 50603 Kuala Lumpur, Malaysia
}

\begin{abstract}
This paper investigates the importance of tribology towards the global economy. The current world energy crisis, the depletion of fossil fuel reserves and the increasing of environmental hazards over the years have urged academicians and scientists to continuously seek for methods to overcome these problems while improving the quality of life in the same time. Energy saving can be achieved through the implementation of tribological improvements in various sectors such as transportation, manufacturing, power generation and residential sectors. The friction reductions eventually lead to wear reduction, energy loss reduction and $\mathrm{CO}_{2}$ emission reduction due to the lesser energy consumption. Therefore, it can be concluded that advanced tribological technologies benefits the entire world in the economical aspect through energy saving and emission reductions.
\end{abstract}

\section{Introduction}

The ever-growing human population, rapid industrialization, modernization and development has increased the demand for energy. It is estimated the total world energy consumption will be increased by $33.5 \%$ from 2010 to 2030 [1]. The earth has been changing for many years until now it is still changing because of modern lifestyle of human. The average temperature of the Earth's surface has increased by about $0.85^{\circ} \mathrm{C}$ in the last 100 years. 2016 became the hottest year on record. Researchers believe that emissions which comprises of greenhouse gases released from industries and agricultural activities are the main cause of greenhouse effect, the way the Earth's atmosphere traps some of the energy from the Sun. Human activities such as the burning of fossil fuels in various sectors are increasing the amount of carbon dioxide $\left(\mathrm{CO}_{2}\right)$, the main greenhouse gas responsible for global warming. Carbon-absorbing forests are also being cut down for development and modernization purposes. The concentration of $\mathrm{CO}_{2}$ in the atmosphere is now higher than at any time in the last 800,000 years. 2016 marked five consecutive years of $\mathrm{CO}_{2}$ increases of at least two parts per million [2].

\footnotetext{
*Corresponding author: masjuki@um.edu.my
} 
Tribology is the science and technology of interacting surfaces in relative motion and the practices are related to friction, lubrication and wear. In order for sustainability, tribology becomes very important in every aspect of life. Tribology exist in all of our daily activities like walking, running, moving, driving and much more. Besides, tribology is also present in many applications such as automotive, industry, sports, cosmetics and biomedical. This proved that tribology is an important consideration in nearly everything around us. Through tribological advancement in reducing friction, product lifespan is increased, therefore saving a lot in terms of replacing broken items, save money from less maintenance required and some other economic benefits.

\section{Global energy consumption, emissions and cost savings.}

According to the Energy Information Administration (EIA), the transportation of people and goods consumes approximately $25 \%$ of total world energy consumption [3]. The increase in number of vehicles contribute to severe environmental pollution. This prompt researchers to study the emissions caused by various transportation vehicles mainly diesel-powered vehicles. The energy consumptions in vehicles are mostly end up as friction losses in engine, transmission and other components as shown in Fig. 1. Half of energy supplied from the fuel combustion was used by the mechanical works and at the end of the cycle, only $34 \%$ of energy is used and the rest (66\%) is considered lost to the surrounding.

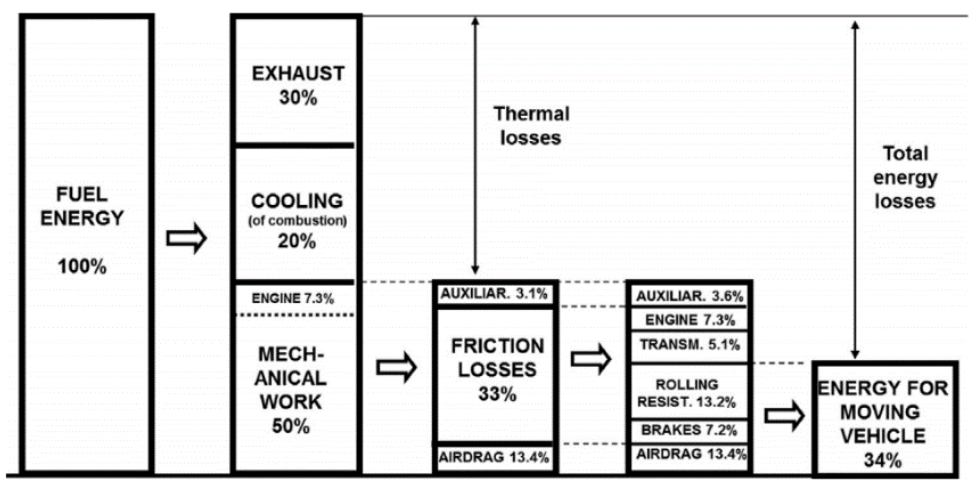

Fig. 1. Percentage of energy consumptions in heavy duty vehicles

By implementing tribological knowledge on vehicles, the energy losses from frictions can be reduced and more energy can be used for moving the vehicles. A reduction of $10 \%$ in friction results in a reduced fuel consumption of $7.4 \%$. Thus, the fuel efficiency and performance of the vehicles can be improved, and more money can be saved. Based on data obtained from 2000 to 2013 and improvements done in research laboratories, coefficient of frictions in heavy-duty vehicles is predicted to reduce from $\approx 0.14$ in 2000 to $\approx 0.01$ by the year 2025. Obviously, with the implementation of tribological knowledge plus the advanced technology nowadays, the predictions will contribute in $13.8 \%$ reduction of fuel consumption $(\approx 2.7$ million TJ/a), equal to 104,500 million Euro per year that can be saved globally and reduction of 196 million tons of CO2 emission [4].

The technological advancements nowadays lead to the findings of new surfaces, materials and lubricants technology for reducing friction and wear in transportation, manufacturing, power generation and residential sector. The energy losses due to friction and wear were predicted to reduce by $18 \%(21.5 \mathrm{EJ})$ in 8 years and $40 \%$ (46 EJ) in 15 years. These reductions were said to caused saving up to $1.4 \%$ of the GDP annually and $8.7 \%$ of the global energy 
consumption for 15 years. Among the four sectors, for 8 years, it was predicted that the largest energy saving is contributed by transportation (25\%), followed by power generation $(20 \%)$ and manufacturing and residential sector by nearly $10 \%$. While for 15 years, the saving can reach up to $55 \%, 40 \%, 25 \%$ and $20 \%$ respectively. Furthermore, the implementation of advanced tribological technologies can reduce emissions by $1,460 \mathrm{MtCO}_{2}(\approx 455,000$ million Euro) and 3,140 $\mathrm{Mt} \mathrm{CO}_{2}(\approx 973,000$ million Euro $)$ in 8 years and 15 years respectively [5].

\section{Friction reduction strategies}

Automotive sector is one of the major consumers of non-renewable energy produced worldwide and significantly contributes in contaminating the environment due to hazardous emissions [6]. Therefore, automotive manufacturers are taking revolutionary steps to develop tribologically advanced materials and environment-friendly lubricants. A significant amount of input energy is lost due to friction in various assemblies such piston ring-cylinder liner, valve trains and fuel injection system. A considerable improvement in tribological performance of automotive engine can be achieved through component surface modifications and/or lubricant oil modifications.

\subsection{Component surface modifications}

Component surface modifications includes the deposition of diamond-like carbon (DLC) coatings on engine components such as tappet, camshaft, piston ring and piston. DLC coatings are renowned for their low-friction coefficients and wear-resistance, which eventually contribute to fuel saving and increased durability of the engine [7].

Another method of surface modification is by texturing which has been used for many years to reduce friction and wear. One famous example is honing process of engine cylinder liner to control engine oil and fuel consumption of an engine. Recently, the utilization of Laser Surface Texturing (LST) has played a significant role in texturing, because of its applicability on almost any materials to produce topographical features as seen in Fig. 2 [8]. The friction and wear can be reduced by the introduction of selective micro-structures on the sliding surfaces using LST [9]. These microstructures act as micro-reservoirs for lubricant in starved lubrication conditions and are expected to assist in the formation of a lubricating film that reduces friction. Also, the microstructures are capable to trap wear debris in either lubricated or dry condition.

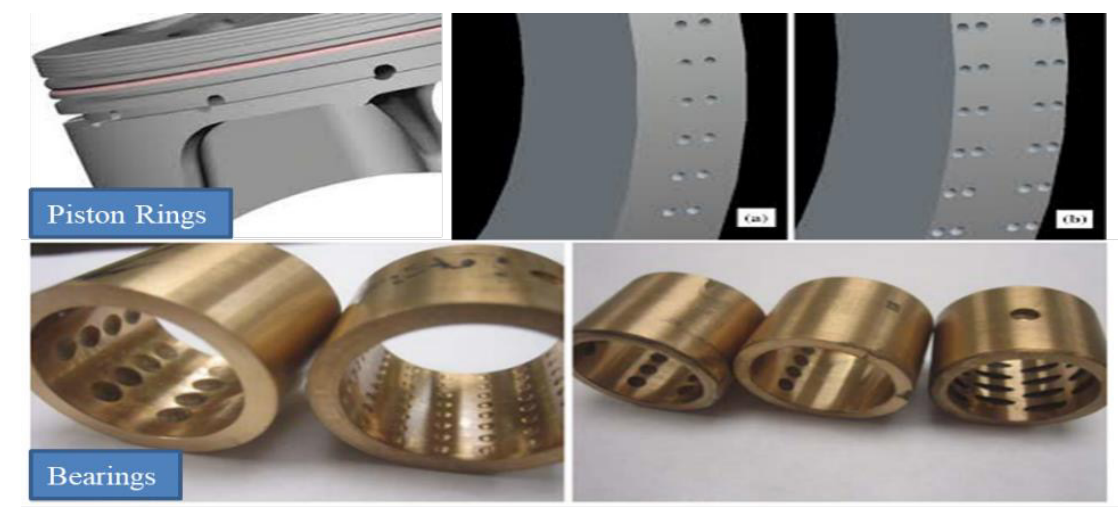

Fig. 2. Surface texturing techniques at piston rings and bearings 


\subsection{Lubricating oil development and modifications}

During operations, lubricant is expected to maintain the effective lubrication for an extended duration before being drained. To fulfil these expectations, the base oil needs to be added with several additives, which must be carefully selected to develop the lubricant with the desired performance. The additive packages have evolved to play an increasingly significant role in the oil formulation.

The gradual depletion of petroleum source and growing concern over environmental hazard has aroused a global widespread concern. Various measures have been taken in order to slow down these imminent threats, including the development of bio-lubricant from the utilization of renewable resources as potential alternative to mineral-based products. In addition to being readily biodegradable and renewable, bio-lubricants are known to have good lubricity, high flash point, high viscosity index and good resistance to shear compared to mineral oils. Despite the advantages, widespread usage of bio-lubricants today is still limited due to major challenges concerning their performance, production scale and lack of encouragement from the authorities. [10].

The quest for energy efficiency has led the research towards new materials to be used as lubricant additives. Nanoparticles are a relatively new class of lubricant additives which offer solution to many problems associated with Sulphur- and Phosphorus-based additives [11]. Nanoparticles are versatile as many researchers have reported that a single type of nanoparticle served multiple purposes as anti-wear, extreme pressure additive as well as friction modifier simultaneously. Nevertheless, it is still a challenging task to select the suitable nanoparticle additive. The effectiveness of nanoparticles depends on a range of factors, such as their compatibility with base oil, their sizes and morphologies, as well as their concentrations [12].

A recent emerging new class of lubricant called ionic liquids (ILs) is gaining popularity due to their superior tribological performance. ILs are composed of large organic cations and smaller size and more symmetrical shape anions held together by intermolecular Van der Waals forces. The exploration of ILs as neat lubricants was started in 2001, prompting many studies of similar objectives. They are proven to outclass the commercial lubricant as they possess unique physical and chemical properties that enables them to perform better, which are; 1) strong surface adsorption due to inherent polarity of ions, 2) low flammability, 3) high thermal stability, 4) stable rheological behaviour due to low sensitivity towards environmental changes [13]. Even though neat ILs were proven to exceed the performance of commercial lubricant, they struggled to make an impact due to their expensive cost. Therefore, using ILs as oil additives has become the new central topic for ILs lubrication.

\section{Moving forward}

Nations around the world need to up their game in the fight against climate change. It is well known that $\mathrm{CO}_{2}$ is the climate's worst enemy. It is released when oil, coal, and other fossil fuels are burned for energy we use to power our homes and cars. By using less of it, we can curb our own contribution to climate change while also saving money. This can be achieved through proper engagement with the public to increase awareness and strict government regulations controlling the release of $\mathrm{CO}_{2}$ and other greenhouse gases in transportation and industrial sectors. Many countries around the world are aware of these and have taken considerable approaches. For example, the newly formed government of Malaysia in 2018 led by Prime Minister Tun Dr. Mahathir Mohamad have included climate change in the revised Ministry of Energy, Technology, Science, Climate Change and Environment in order to tackle this issue during their tenure. 
Additionally, government policies should support innovation by continuously reforming and updating the regulatory and institutional framework within which innovative activities take place. This can be done by using developed countries like Japan and Germany as benchmark for structuring curriculum framework regarding vision and mission of research. Special incentives can be offered to industry or university to increase spending on research largely because $R \& D$ and innovation are considered key for productivity and growth performance. Such action can indirectly nurture the competitive mindset among researchers whose motivated by various supports and incentives.

\section{Conclusion}

Tribology is an important field to be practiced in all sectors since it is beneficial to the entire world in various aspects. Through tribology, energy saving and greenhouse gases (GHG) emission reductions can be achieved. Thus, environmental destructions can be avoided. However, efforts still need to be taken by various bodies in order to propel tribologyrelated research for a better and greener tomorrow.

\section{References}

1. Saidur, R., E.A. Abdelaziz, A. Demirbas, M.S. Hossain, and S. Mekhilef, Renew Sust Energ Rev. 15 2262-2289 (2011)

2. BBC. Six graphics that explain climate change. 10 July 2018; Available from: https://www.bbc.co.uk/news/resources/idt-5aceb360-8bc3-4741-99f0-2e4f76ca02bb.

3. J. Conti, P. Holtberg, J. Diefenderfer, A. LaRose, J.T. Turnure, and L. Westfall, International Energy Outlook 2016 with Projections to 2040, (2016)

4. Holmberg, K., P. Andersson, N.-O. Nylund, K. Mäkelä, and A. Erdemir, Tribol Int. 78, 94-114, (2014)

5. Holmberg, K. and A. Erdemir, Friction. 5(3), 263-284, (2017)

6. Zulkifli, N., M. Kalam, H. Masjuki, M. Shahabuddin, and R. Yunus, Energy. 54, 167173, (2013)

7. Love, C.A., R.B. Cook, T.J. Harvey, P.A. Dearnley, and R.J.K. Wood, Tribol Int 63, 141 150, (2013)

8. Joshi, B., K. Tripathi, G. Gyawali, and S.W. Lee, Pro Nat Sci-Mater. 26(4), 415-421, (2016)

9. Ramesh, A., W. Akram, S.P. Mishra, A.H. Cannon, A.A. Polycarpou, and W.P. King, Tribol Int. 57, 170-176, (2013)

10. Syahir, A., N. Zulkifli, H. Masjuki, M. Kalam, A. Alabdulkarem, M. Gulzar, L. Khuong, and M. Harith, J Clean Prod. 168, 997-1016, (2017)

11. Joly-Pottuz, L., B. Vacher, N. Ohmae, J.M. Martin, and T. Epicier, Tribol Lett. 30(1), 69$80,(2008)$

12. Gulzar, M., H.H. Masjuki, M.A. Kalam, M. Varman, N.W.M. Zulkifli, R.A. Mufti, and R. Zahid, J Nanopart Res. 18(8), 223, (2016)

13. Zhou, Y. and J. Qu, ACS Appl Mater Inter. 9(4), 3209-3222, (2017) 